\title{
Acanthamoeba polyphaga mimivirus and other giant viruses: an open field to outstanding discoveries
}

\author{
Jônatas S Abrahão ${ }^{1 *+}$, Fábio P Dornas ${ }^{1 \dagger}$, Lorena CF Silva ${ }^{1 \dagger}$, Gabriel M Almeida ${ }^{1}$, Paulo VM Boratto ${ }^{1}$, Phillipe Colson², \\ Bernard La Scola ${ }^{2}$ and Erna G Kroon ${ }^{1}$
}

\begin{abstract}
In 2003, Acanthamoeba polyphaga mimivirus (APMV) was first described and began to impact researchers around the world, due to its structural and genetic complexity. This virus founded the family Mimiviridae. In recent years, several new giant viruses have been isolated from different environments and specimens. Giant virus research is in its initial phase and information that may arise in the coming years may change current conceptions of life, diversity and evolution. Thus, this review aims to condense the studies conducted so far about the features and peculiarities of APMV, from its discovery to its clinical relevance.
\end{abstract}

Keywords: Giant viruses, Mimiviridae, Mimivirus

\section{Introduction}

Viruses are remarkable organisms that have always attracted scientific interest. The study of unique viral features has been a wellspring of discovery that helped establish the foundations of molecular biology and led to in-depth evolutionary studies [1-3]. In this context, giant viruses have recently emerged as a fascinating line of research, raising important questions regarding evolution and their relationships with their hosts [4-10].

Although giant viruses offer deep ecological and clinical importance, the Mimiviridae group deserves special emphasis; they have been the subject of intense research in recent years, which has generated much relevant information [4-8,11-14]. Acanthamoeba polyphaga mimivirus (APMV) was the first known mimivirus, isolated from an amoebal co-culture present in a water sample collected from a cooling tower of a hospital in England. Its characterization revealed surprising characteristics: it was a DNA virus with a diameter of approximately $700 \mathrm{~nm}$ and a genome of approximately $1,2 \mathrm{Mb}$, making it the largest known virus up

\footnotetext{
*Correspondence: jonatas.abrahao@gmail.com

${ }^{\dagger}$ Equal contributors

'Universidade Federal de Minas Gerais, Instituto de Ciências Biológicas, Laboratório de Vírus, Avenida Antônio Carlos, 6627, Caixa Postal 486, Bloco F4, Sala 258, 31270-901 Belo Horizonte, Minas Gerais, Brazil

Full list of author information is available at the end of the article
}

to then [5]. Five years later, a similar virus was isolated in amoeba from the water of a cooling tower in Paris, and since then several dozen giant viruses have been isolated from many different environments and specimens [11,15-19]. Data obtained from these viruses provoked scientific discussions regarding the nature and biological dynamics of viruses, and the intriguing features Mimivirus have challenged virologists and evolutionists alike. The potential existence of many other interesting and unusual unknown viruses in the biosphere makes us realize that the discovery and characterization of giant viruses is in its initial phase and that there is still much to be learned by studying these organisms. Recently, the discovery of Pandoravirus $(1 \mu \mathrm{m}$ in length and with a genome fo $2.8 \mathrm{Mb}$ ) and of Pithovirus sibericum $(1.5 \mu \mathrm{m}$ in length and a surprisingly smaller genome of $600 \mathrm{~kb}$ ) brought even more attention to the prospection and study of giant viruses $[19,20]$.

\section{Discovery and taxonomy}

In 1992, a pneumonia outbreak occurred in a Bradford hospital (England), and water samples from a cooling tower that contained free-living amoebae were investigated to determine the etiological agent of the pneumonia outbreak [5]. At that time, Gram-positive cocci that were visualized by light microscopy inside Acanthamoeba polyphaga cells 
were named Bradford coccus. Every attempt to isolate this microorganism and amplify its $16 \mathrm{~S}$ rDNA failed. Moreover, treatment of amoeba cultures with antibiotics to inhibit growth of this microorganism was also unsuccessful, which led doubt whether it was indeed a bacteria [5]. After a hiatus of a few years, this organism was the subject of new studies at the Rickettsia Unit at the School of Medicine (Marseille, France) in the early 2000s. After a new series of unsuccessful characterization attempts, electron microscopy of Bradfordcoccus-infected Acanthamoeba polyphaga cells revealed icosahedral-like particles with an astonishing $750 \mathrm{~nm}$ diameter size [5]. In addition to this virus-like morphology, analysis of the replication curve of this organism in amoeba cells revealed an eclipse phase, which is an almost universal feature among viruses. Finally, when the complete sequencing and analysis of its genome was finished, it became evident that this peculiar organism clustered with other giant viruses and not with bacteria [5]. This new virus was then called Acanthamoeba polyphaga mimivirus (APMV), due its ability to infect the free-living amoebae Acanthamoeba polyphaga sp. and mimic a microbe. APMV, also known as mimivirus, had the largest viral genome known up to then, reaching approximately 1.2 Mb. Its characteristics were so different from other viruses that it was not possible to include it into any known viral family, so the Mimiviridae family was created [5]. APMV became the first member of the Mimiviridae family, Mimivirus genus, and its prototype.

Few years before the discovery of APMV, the genomic content of known giant viruses that replicate partly or entirely in the cytoplasm of eukaryotic cells (members from Poxviridae, Asfarviridae, Phycodnaviridae, Ascoviridae and Iridoviridae families) was analyzed in depth. Several common, and supposedly essential, genes were identified, and it was suggested that the origin of these four viral families was monophyletic [21-26]. Other common characteristics, such as a large double-stranded DNA genome, the relative independence of their host transcription machinery, and a replication cycle that occurs at least partially into the cytoplasm with the formation of inclusion bodies or viral factories, were the basis for the generic name of these viral families: the nucleocytoplasmic large DNA viruses (NCLDVs) [22-26]. Because viruses from the Mimiviridae family also share these characteristics, they were added to the NCLDV group as well.

After APMV was described, interest in giant viruses grew, several other giant viruses were isolated, and the Mimiviridae family was expanded. Currently, the Mimiviridae family contains two genera according to the International Committee on Taxonomy of Viruses (ICTV): Mimivirus, with APMV as its only member, and Cafeteriavirus, with Cafeteria roenbergensis virus as its only member (www.ictvonline.org). With the increasing number of new giant virus isolates and hypothetical species, a new viral order has been proposed [27]. The putative Megavirales order contains the Mimiviridae family and other NCLDVs, including the newly proposed Marseilleviridae family [28], whose founding member is Marseillevirus, another giant virus, smaller than Mimivirus, that infects amoeba isolated from cooling tower water in 2008 [18]. Mimivirus and Marseillevirus have been primarily linked to other NCLDVs, based on a set of $\approx 50$ conserved core genes shared by all or by a majority of these large and giant viruses [29]. All these viruses were shown to compose a monophyletic group [21]. Nucleo cytoplasmic virus orthologous groups (NCVOGs) were defined among these viruses, including 177 proteins present in $>1$ NCLDV family and five common to all viruses [30].

The discovery of new isolates of mimiviruses of amoeba revealed the existence of three different lineages (A, B and C). Lineage A of the Mimivirus genus contains the best known mimivirus isolates, such as the APMV species [5]. Mimivirus lineage B is represented by Acanthamoeba polyphaga moumouvirus, which was isolated from a water sample in February, 2008; genetic analysis revealed differences that placed this virus into the B lineage [15]. The first extensively described member of lineage $C$ was Megavirus chilensis, isolated from a water sample collected off the coast of Chile [13]. Other previously described mimiviruses, including Courdo7, Courdo11, Terra1 and Montpellier, were also included in lineage $C$ [31]. Other viruses, including some that are distantly related, have been obtained from environmental and clinical samples [32,33], and in the next years it will likely be possible to present an extensive depiction of the putative viral isolates, strains and species.

\section{Amoebas as the main host of giant viruses}

As mentioned above, the first mimivirus isolate was discovered from studies of the pathogenic microorganisms associated with amoebae (MPAAs) that were linked to nosocomial pneumonia [5]. Free-living amoebae of the genus Acanthamoeba belong to the Protist kingdom and can be part of the normal microbiota of some animals, including humans [34]. Amoebas from this genus are considered ubiquitous and have been isolated from various environments, including soil, air, aquatic environments, sewage treatment systems, contact lenses, hospital environments, and ventilation and air conditioning systems [34-36]. Several studies show that amoebas of this genus are very stable after treatment with disinfectants and are highly resistant to extremes of $\mathrm{pH}$ and temperature [34-37].

Free-living amoebae can cause severe and chronic diseases by themselves, such as granulomatous amoebic encephalitis, cutaneous acanthamoebiasis, amoebic keratitis and primary amoebic meningoencephalitis [38]. They can also carry other MPAAs that cause disease [39-41]. For example, microorganisms of the Legionella, Parachlamydia 
and Mycobacterium genera are MPAAs considered to be causative agents of pneumonia, most of which is associated with many cases of nosocomial lung infection [37,42,43]. Even after being phagocytosed, some MPAAs are able to persist in the amoeba intracellular environment, and often manage to multiply numerously [5]. Studies have described amoebae isolation from many health institutions, revealing the presence of free living amoebae on hospital floors and objects, in intensive care units (ICUs), operating rooms, nurseries, kitchens, emergency rooms and infectious disease wards, showing that the free living amoebas may serve as potential platforms for amplification of pathogenic MPAAS in these environments [40-43]. The attention given to free living amoebas in recent years, together with the isolation and characterization of mimiviruses in amoebal samples from a cooling tower during an outbreak of pneumonia, add more importance to the role of mimiviruses as MPAAs.

Up to now, amoebae of the Acanthamoeba genus are the only confirmed APMV hosts; the virus was originally isolated from $A$. polyphaga, but now is also being cultivated in the laboratory in A. castelannii, A. griffin and $A$. lenticulata $[5,44]$. However, there is increasing evidence that these viruses have a broader host range. Some studies have indicated sponges and corals as potential hosts of mimivirus [44]. Khan (2007) described a productive APMV infection in mice after intracardiac infection [45]. The ability of APMV to enter and replicate inside human phagocytic cells and peripheral blood mononuclear cells in vitro has been reported [39]. These reports, together with the human blood isolation of the marseillevirus, another giant virus of amoeba belonging to a different family, suggests that vertebrates may also be hosts of these viruses [46]. The mimivirus genome has been detected in monkeys and bovines, supporting these findings $[47,48]$. Recently, it has been shown that APMV is able to interact with the human interferon system, a strong clue that both species share an evolutionary history [49]. It appears that APMV's ability to enter cells by phagocytosis without identified specific cell receptors, together with its large genome that confers a powerful array of non-essential genes, permits APMV to exploit a larger host range than initially believed $[39,49]$. Lastly, as described in this review, there is ample evidence associating APMV and other mimiviruses with humans, especially regarding pneumonia cases [50-57].

\section{Viral particle structure, genome and gene expression}

The remarkable size of mimiviruses and their peculiar features make them unique among viruses. First of all, their enormous size of approximately $700 \mathrm{~nm}$ lets them be retained on $0,2 \mu \mathrm{m}$ filters [5] (Figure 1-A to D). APMV particles do not have an outer envelope, but fibers of approximately $120 \mathrm{~nm}$ can be associated with the capsid [58,59] (Figure 1-A and B). These fibers, still under investigation, may be involved in viral adsorption to substrates. APMV encodes enzymes capable of synthesizing polysaccharide complexes found in bacterial lipopolysaccharide (LPS) and/or peptidoglycan [60-63]. These polysaccharides form the viral particle's outer layer, in which the fibers are embedded, and they may also serve as a phagocytosis stimulus [58-63]. APMV has a pseudo-icosahedral symmetry, with a complex pentagonal face region named stargate $[60,63]$. This stargate form is a star-shaped projection from which the viral genome is released, and it can be important during early stages of the viral replication cycle $[60,61,63,64]$ (Figure 2).

The particle also contains internal membranes surrounding the genome, likely acquired from endoplasmic reticulum [62] (Figure 1-A and B). The number of lipid membranes inside mimivirus particles is still under debate and investigation. At least three protein layers surround the internal membrane, and the fibrils are projected from the external layer in a tussock-like organization [62] (Figure 1B). Inside the APMV membrane, a core wall envelops the viral DNA $[62,63]$. Some authors conjecture that APMV's unique particle structure may reflect horizontal gene transfer (HGT), especially amongst organisms that share the intracellular environment of amoeba, though adaptative convergence should also be considered. The APMV genome is found in association with a fibrous matrix, resembling the structure of most eukaryotic genomes; the genome release by the stargate mechanism is similar to genome releases in certain bacteriophages, and the peptidoglycan matrix surrounding the external fibers is similar to that found in certain bacteria [63].

This large and complex particle structure seems to be vital for viral stability and genome integrity under adverse environmental conditions [65-67]. The APMV genome consists of a double-stranded DNA molecule of approximately $1,2 \mathrm{Mb}$ that encodes approximately 1000 proteins, many of them still uncharacterized or having functions never observed before in other viruses $[5,68]$. Four main groups of ORFs can be delineated in the APMV genome: (i) Megavirales core genes; (ii) genes involved in lateral gene transfer; (iii) duplicated genes; and (iv) ORFans [69]. Some APMV encoded proteins are involved in protein translation, DNA repair, cell motility and membrane biogenesis [68-72]. Many of these proteins are likely non-essential for viral replication, but may possibly increase viral fitness. Some APMV genomic sequences exhibit little or no homology with any other known nucleotide sequences in the current databases, and thus are called ORFans [69-72]. The presence of genes encoding proteins involved in protein translation, such as the amino-acyl tRNA synthetase (aaRS) and 

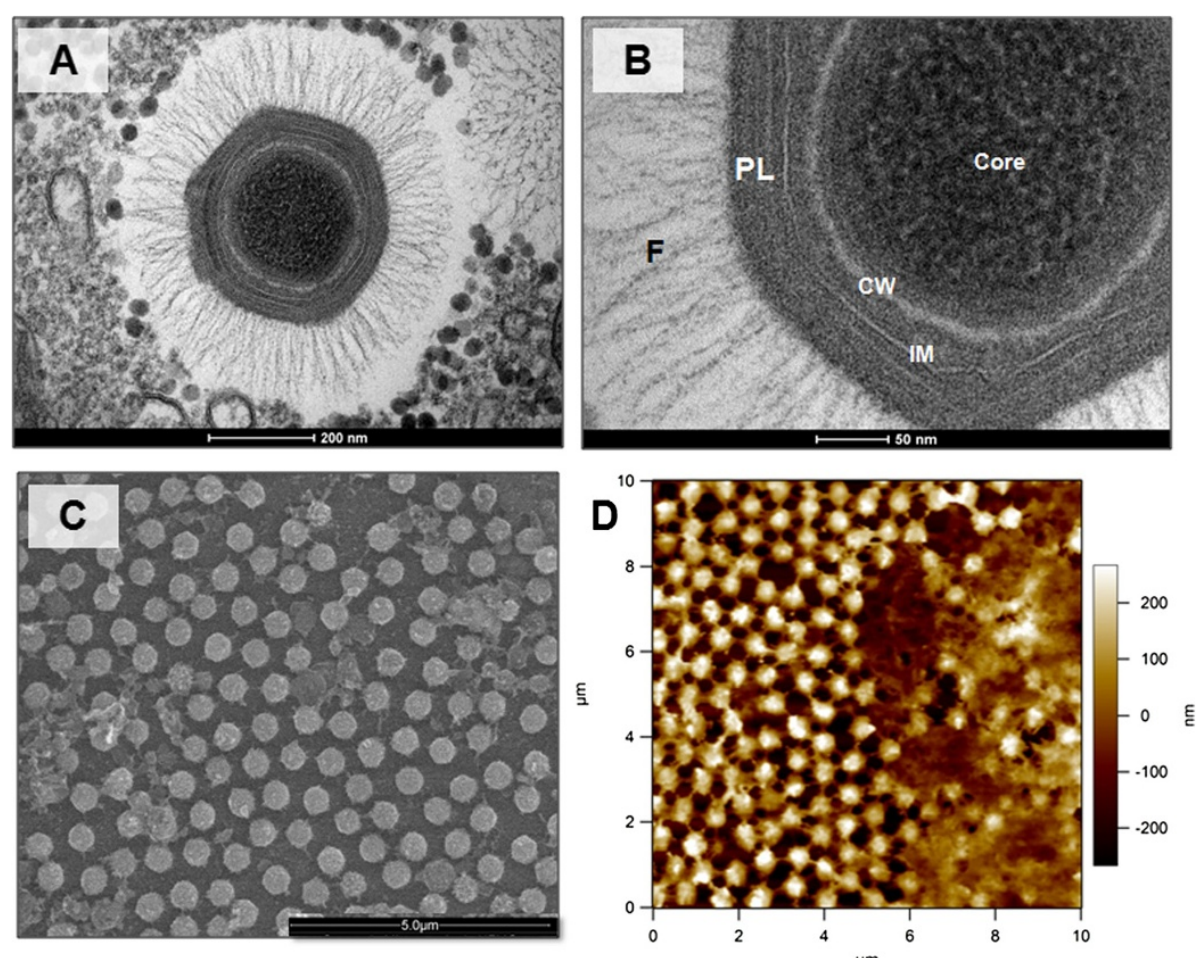

Figure 1 Mimivirus particle visualized by different microscopy methods. Transmission electron microscopy of APMV showing the complete particle (A) and a zoom (B), highlighting the fibrils (F), the capsid protein layers (PL), the internal membrane (IM), and the core wall (CW) that protects the viral genome and early factors. (C) and (D) show mimivirus isolates under scanning and atomic force microscopy, respectively. Scale in (D) represents the sample depth and size.
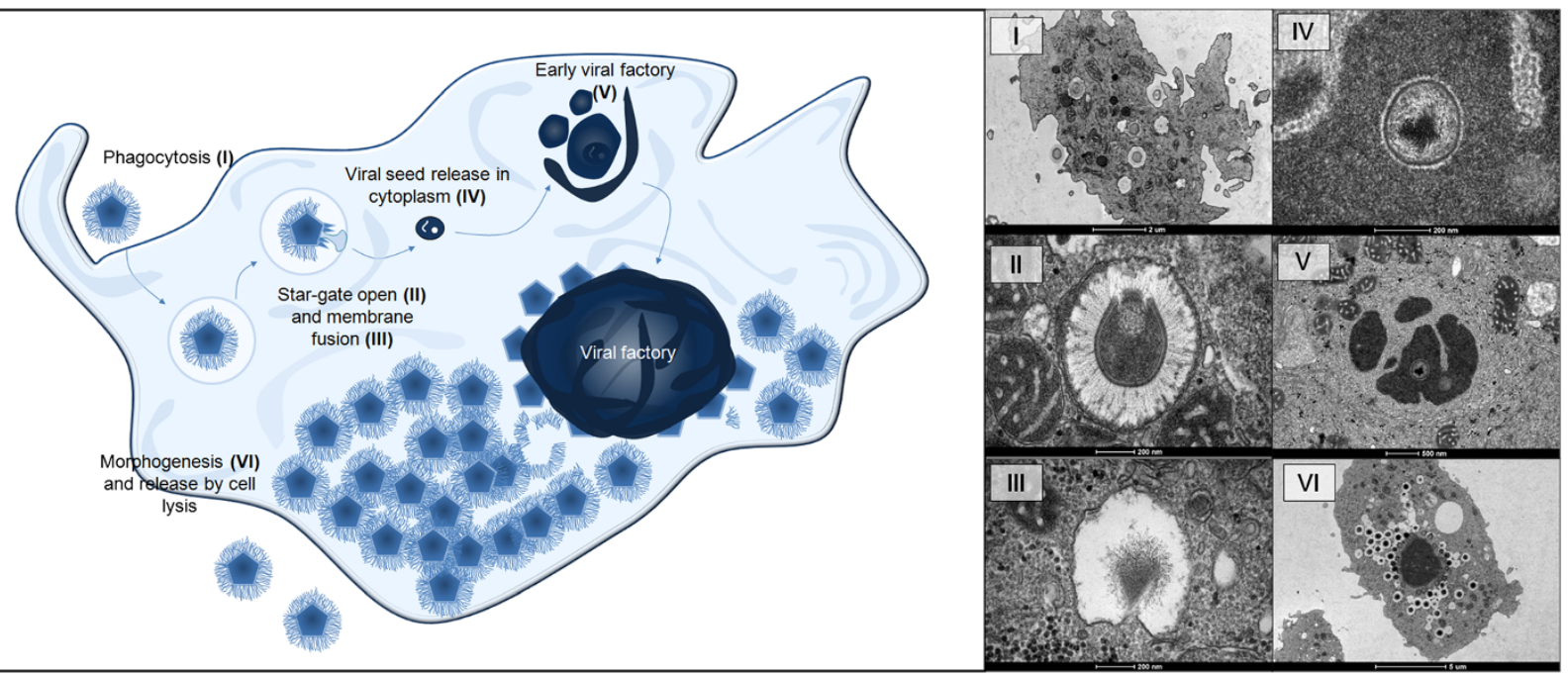

Figure 2 Mimivirus replication cycle in amoebas. (I) Phagocytosis. (II) Virus entry into a phagosome, followed by star-gate opening and viral membrane fusion (III). (VI) Viral seed is released in the amoeba cytoplasm and gives start to an early viral factory (V). After few hours, the viral factory grows and orchestrates the morphogenesis (VI) of the viral progeny, which are released by cell lysis. At the right, transmission electron microscopy of APMV at its different steps of the replication cycle. 
translation factors, confers to APMV a degree of independence from their host cell machinery for genome replication $[73,74]$.

No previously described viral genomes have shown a genetic arsenal that is able to encode elongation factors, such as tRNA and aaRS; those viruses instead must directly rely on host elongation factors. A substantial proportion of the Mimivirus, and Marseillevirus, ORFs have homologs in bacteria, archaea, eukaryotes or viruses. The large amount of chimeric genes in these viral genomes may have resulted from acquisitions by lateral gene transfer, implying sympatric bacteria and viruses with an intra-amoebal lifestyle [69].

The genomes of APMV and other mimiviruses have a high adenine-thymine (AT) content, with their most frequent codons being AAA (lysine) and AAT (asparagine). Both the codon and amino acid usages of mimiviruses are highly dissimilar to those of their amoebal host, Acanthamoeba castellanii, and instead are correlated with the high adenine and thymine (AT) content of the mimivirus genomes [73,75]. Additionally, it has been demonstrated that the Leu(TAA)tRNA present in several mimivirus genomes, and in multiple copies in some viral genomes, may complement the amoebal tRNA pool and may help accommodate the AT-rich viral codons [75]; remarkably, the genes most highly expressed at the beginning of the mimivirus replicative cycle have a nucleotide content more adapted to the codon usage in $A$. castellanii. Recently, an interesting study evaluated genomic alterations in APMV maintained for 150 successive passages in an axenic amoebal culture in an allopatric system. It was shown that the genome was reduced in size and morphological changes occurred in the viral particle [76]. In the allopatric system, there was no competition with other intra-amoebal micro-organisms, including bacteria and other viruses; nor were there major sources for gene gain and replacement from those micro-organisms. The passaged APMV had large deletions towards the APMV genome extremities and gene losses that were associated with: loss of fibers and their glycosylation; decreased viral ability to associate with virophages; and decreased particle antigenicity, likely due to fiber loss [76]. Excluding large deletions, $77 \%$ of the APMV genes remained intact after 150 passages in amoeba, $23 \%$ had variability and $10 \%$ were predicted to have inactivated. A majority of these inactivated genes had been previously described as weakly transcribed in APMV, prior to the laboratory culture under allopatric conditions [68,77]. In contrast, most of the genes highly transcribed before this laboratory culture were not inactivated. The major loss of weakly transcribed and weakly expressed genes in allopatric conditions suggests that the virus tends to lose or degrade its useless genes in a Lamarckian evolutionary process [77]. The loss can also be explained by the fact that DNA repair is most common in actively transcribed regions, so it is expected that genes exhibiting lower transcriptional levels undergo more changes [76,77].

\section{Viral replication cycle}

Although APMV is also unique in its replication cycle, there is a resemblance to the poxvirus replication cycle [78] (Figure 2). It has been demonstrated that APMV enters amoebas of the Acanthamoeba genus through phagocytosis (Figure 2-I), and the initiation of the replication cycle is marked by a typical eclipse phase, in which viral particles are not viewed in the cell $[5,39]$. In the early stages of replication, phagocytosed viral particles can be detected within phagosomes inside the host cell until the star-gate channels in the viral capsids (Figure 2-II) open, which is followed by membrane fusion (Figure 2-III) and release of viral seeds containing the genomes into the cytoplasm of the host cell (Figure 2-IV) [78]. DNA replication occurs exclusively in the cytoplasm, although it cannot be considered totally independent of the host nucleus because nuclear factors required for replication might participate in the process. It has been demonstrated that multiple vesicles start to appear in the cytoplasm approximately 2 hours after infection $[5,78]$. Their origins are unknown, but it is suspected that they are derived from the nuclear membrane or endoplasmic reticulum, and these vesicles seem responsible for nuclear factor transportation to the viral factories $[78,79]$. Atomic microscopy of infected amoebas revealed that the nuclear morphology does not change during the APMV infection cycle [80]. Following uncoating, the genome stabilized in viral seeds initiates the viral factories (Figure 2-V factory in formation; 2-VI mature factory). In these factories, viral DNA undergoes replication and transcription, and the DNA is prepared to be packaged in procapsids through a non-vertex portal, a transient aperture centered at an icosahedral face distal to the DNA delivery site, suggesting a pathway reminiscent of DNA segregation in bacteria $[63,64,78,79]$.

The transcription occurs in a temporal manner: early, intermediate and late stages [80]. Interestingly, it was demonstrated that mimivirus gene promoters exhibit an unprecedented conservation among all eukaryotes [80]. After the expression of late genes, there is an increase in viral factories and structural proteins are synthesized, initiating the process of viral morphogenesis, followed by packaging of capsids with DNA (Figure 2-VI). During morphogenesis, membrane generation is accompanied by the assembly of icosahedral viral capsids, a process involving the hypothetical major capsid protein L425 that acts as a scaffolding protein [33]. An assembly model was proposed explaining how multiple mimivirus progeny can be continuously and efficiently generated. There is a high accumulation of virions in final stages of 
morphogenesis [78] (Figure 2-VI). It was also demonstrated in an interesting study, that professional phagocytes such as vertebrate monocytes and macrophages are permissive for APMV replication, becoming infected via phagocytosis that leads to productive infections [39]. Ultrastructural analysis showed that protrusions were formed around the entering virus, suggesting that macropinocytosis or phagocytosis was involved in APMV entry. Reorganization of the actin cytoskeleton and activation of phosphatidylinositol 3-kinases were required for APMV entry [39]. However, although it has been shown that APMV is able to interfere with the IFN system in vertebrate cells, further studies are necessary to understand the mechanisms involved in viral replication in vertebrate phagocytes [49].

\section{The role of giant viruses in aquatic ecosystems}

The isolation of giant viruses from many different specimens, ranging from environmental samples to unicellular eukaryotic green algae and even vertebrates, reveals their ubiquitous presence on this planet. To date, we have isolated many giant viruses from aquatic environments in Brazil, especially from urban lagoons and acidic rivers, suggesting an association between a high degree of organic matter and giant virus detection [81] (unpublished data). However, discovery of mimiviruses raises questions about their ecological and evolutionary roles, especially in oceans. Carbon transfer and nutrient recycling are important biogeochemical processes that deeply involve marine zooplankton and phytoplankton [82,83]. Viruses are key regulators of these processes, due to their ability to infect and kill these populations, but the full extent of their role is still unknown $[82,83]$. The discovery of giant viruses in fresh and salt water provoked intense debate about the ecology of these viruses in aquatic systems, as well as their roles in structuring protist populations and even in gene exchange. In recent studies, it became evident that giant viruses can infect host protists, as in the case of the Cafeteria roenbergensis virus infecting marine unicellular chlorophyll flagellates [84]. It was suggested that the APMV group also contains closely related viruses capable of infecting phytoplankton, and these viruses groups phylogenetically with certain viruses of unicellular and multicellular algae [85]. Metagenomic studies, conducted in 2005 during the Global Ocean Sampling expedition in the Sargasso Sea, demonstrated through phylogenetic analysis that DNA viruses that are evolutionarily close to mimivirus exist in nature $[10,86,87]$.

Several mimivirus-like sequences were identified, suggesting that these viruses are abundant in the marine environment. This key finding suggests that further studies of these genomic sequences can reveal the diversity of these DNA viruses and their possible roles in the evolution of eukaryotes [86]. To a lesser extent but similar to the interaction of phages and bacteria, prokaryotes that are lysed by the multiplication of marine mimiviruses could result in increased dissolved carbon and nutrients in surface waters, which might reduce sedimentation, promote microbial growth and impact local communities.

\section{Giant viruses and the contribution to evolution knowledge}

Canonically, it is considered that the genomes of most viruses do not contain sufficient information to support their classification into a domain of life. However, with the discovery of APMV and other giant viruses, this topic is being debated [24,26,88]. Giant viruses have genes that are common to the three classical Domains of life: Archaea, Bacteria and Eukarya, including genes involved in information storage and processing. For some researchers, this phenomenon puts them in the same definition of life that is assigned to those Domains [26]. Some APMV genes are notable due their hypothetical evolutionary importance. Recent studies have indicated the existence of a host-independent glycosylation system in APMV, likely acquired very early during evolution [89]. Collagen, one of the most abundant proteins in living cells, is found in APMV and undergoes a new type of glycosylation, showing for the first time that post-translational collagen modifications are not restricted to the canonical domains of life [90]. These results indicate that mimiviruses may have contributed to the evolution of collagen biology [90]. Genes coding for proteins involved in the replication and repair of DNA, such as DNA polymerase B and topoisomerase II, and genes for the thymidine synthetase enzymes involved in the biosynthesis of DNA oligonucleotides, are typical of eukaryotic cells but are also found in giant viruses [73]. A phylogeny based on these proteins results in an exclusive clade for the giant viruses, distinct from Eukarya, Bacteria and Archaea [26].

Analysis of the transcription factor II B, absent in Bacteria, suggests that it is highly conserved and forms a clade as old as Eukarya and Archaea itself [88]. Analysis of the aaRS genes reveals similarity between Mimiviridae, Amoebazoa and Eukarya. It supports the possibility that these genes may have been transferred from a viral ancestor to amoebae, suggesting that these exchanges are common [88]. However, this specific gene has been described as involved in a lateral gene transfer. These intriguing results led some authors to question the comprehensiveness of phylogenetic trees based on analysis of ribosomal RNA because they exclude viruses and do not seem sufficient to represent all forms of life and to propose a fourth domain of life based on phylogenetic and phyletic analyses of informational genes [24,26,88]. The current classification, based on patterns of similarity of ribosomal RNA, is a prejudiced approach because it 
excludes viruses from the living organisms, as viruses do not harbor ribosomal genes. However, the proposition of a fourth Domain of life to accommodate giant viruses is still much in debate. Some authors believe that the fourth domain may be artifactual, due to compositional heterogeneity and homoplasy, and the use of genes possibly acquired by the viruses from their eukaryotic hosts by horizontal gene transfer (HGT) [88].

\section{Virophages}

The isolation of Acanthamoeba castellanii mamavirus (ACMV) led to the discovery of one of the most intriguing and differentiating features of the Mimiviridae family: its close association with other small viruses called the Sputnik virus. Sputnik virus was first identified as a satellite virus [11]. Its replication, associated with the Mimivirus factories inside amoebas, resembled satellite viruses that affect animals and plants. However, Sputnik virus replication appears to impair the normal morphogenesis and production of Mimivirus, a process closer to true parasitism than to the previously known satellite viruses. From a biological view, the infection with Sputnik virus results in $\sim 70 \%$ reduction of the cytopathic effect of the giant viruses in amoeba and leads to formation of some atypical viral forms, in a way never described for traditional satellite viruses $[11,12]$. This discovery led to the creation of the term "virophage", which means a virus able to 'infect' other viruses $[11,12]$. Sputnik virus is an icosahedral virus $50 \mathrm{~nm}$ in diameter and a genome of $18 \mathrm{~kb}$, which contains a mosaic of genes related to bacteriophages, other viruses and amoebae. Its genome is circular double-stranded DNA that is hypothetically able to encode 21 proteins, some of which have no detectable homologues in current databases of nucleotide sequences $[11,12]$.

Recently, we have isolated Rio Negro virophage associated with Samba virus, an APMV strain from the Brazilian Amazon [81]. Other described virophages are parasites of the giant viruses (phycodnaviruses and mimiviruses) [32] and might control the dynamics of Antarctic alga species. Mavirus is a virophage that parasitizes the giant Cafeteria roenbergensis virus [91]. On the basis of genetic homology, Mavirus likely represents an evolutionary link between double-stranded DNA viruses and Maverick/Polinton eukaryotic DNA transposons [91]. It has been shown that giant viruses may even have virophages inside their own mobile genetic elements. A 2013 study of the mobilome of Lentille virus revealed that a virophage, Sputnik 2, is part of this genetic element [14]. It was observed by FISH that the virus and its virophage replicate in the same viral factories and are detected in the cytoplasm of the host cell, suggesting that Sputnik 2 was integrated into the Lentille virus genome [14]. This was confirmed by genome digestion of these viruses, followed by Southern blotting and 2D gel analysis. Lentille virus was sequenced on different platforms, and a sequence related to Sputnik2 was integrated in its genome, thus suggesting that Sputnik2 is a provirophage. These analyses also revealed that Lentille virus (and a small fraction of Sputnik2) contained an extrachromosomal DNA rich in CG that was called a transpoviron (an equivalent of transposon in viruses from our point of view), which can undergo recombination with Sputnik2 and many other organisms [14]. Phylogenetic analysis of the virophages and related genetic elements is compatible with the concept of a network-like evolution in the virus world and emphasizes multiple evolutionary connections between bona fide viruses and other classes of capsid-less mobile elements. Thus, giant viruses appear to present a complex mobilome, which could contribute to gene exchanges that are common in these viruses. Further investigation of these elements will possibly lead to new discoveries, including novel classes of mobile elements, thanks to the diversity and complexity of giant viruses and their virophages [92].

\section{Clinical significance}

Hospitalized patients are a risk group for nosocomial infections, including those caused by amoeba-associated pneumonia agents [54,93]. APMV is a putative pneumonia agent and studies associating this virus with human pneumonia cases are still under investigation [51,54,55,94-97]. APMV genetic material (once) and antibodies against APMV have been detected in samples from patients who had pneumonia without any known cause (bacterial, viral or fungal); these patients came from different locations and were studied by different research groups, lending strength to the possible role of APMV as a pneumonia agent $[54-57,98]$. The genetic diversity among the Mimiviridae members needs to be considered when interpreting negative PCR tests in several studies because the diversity may have impaired detection of APMV-related DNA [29]. An animal model for mimivirus pneumonia studies has been proposed. When various routes of infection were tested, the intracardiac infection route induced pneumonia in C57/B6 mice [45]. Although this model does not exactly simulate the hypothetical natural route of mimivirus infection, it was possible to observe histopathological evidence of acute pneumonia, isolate the virus and detect antigens by indirect immunofluorescence assay [45].

The first studies in which a giant virus was successfully isolated from a human specimen were published in 2013 [50,52]. In a first study, a total of 196 samples from patients were collected in Tunisia between 2009 and 2010; virus was detected by the formation of plaques in monolayers of amoeba grown on agar plates [52]. The isolated virus (LBA111) was found in a sample obtained from a 72-year-old patient with pneumonia. Serology and real time PCR confirmed the presence of a giant virus in this 


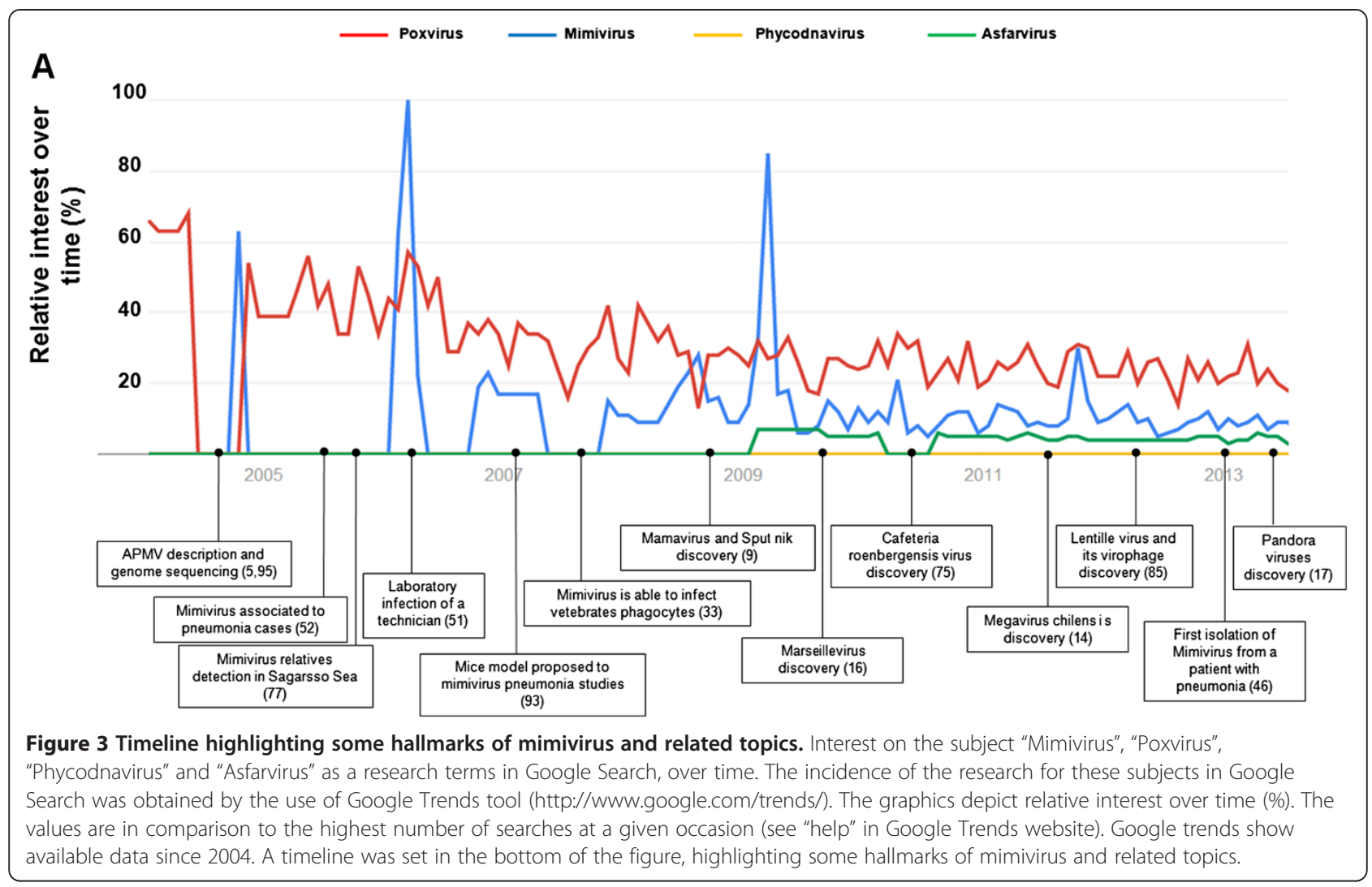

sample. LBA111 has a similar morphology to other mimiviruses, with a size of approximately $560 \mathrm{~nm}$ and a genome of 1,23 Mb. Western blot analysis showed positive immunoreactivity of patient sera against specific proteins of both APMV and LBA111 [52]. In another study, Shan virus was isolated from a stool sample collected from a Tunisian patient with pneumonia [50]. Metagenomic analysis of a human stool sample revealed the presence of sequences similar to those of giant viruses. From these samples, a virus was isolated and named Senegalvirus [53]. Its characteristics linked it to the Marseilleviridae family, representing the first detection of a marseillevirus from a human sample [53].
Additionally, a blood sample from an apparently healthy donor revealed the presence of Marseillevirus-like DNA; antigens from this virus were detected, it was visualized by microscopy and it grew in human $\mathrm{T}$ cell lymphocytes [46].

The potential clinical relevance of mimivirus can also be analyzed by studies involving the host-virus relationship. In 2008 , it was observed that APMV is internalized by professional phagocytic cells such as macrophages, but not by non-phagocytic cells like fibroblasts, epithelial or neuronal cells [39]. This suggests that these professional phagocytic cells can be targets for APMV replication in humans. Analysis of 'infected' macrophages revealed that viral DNA
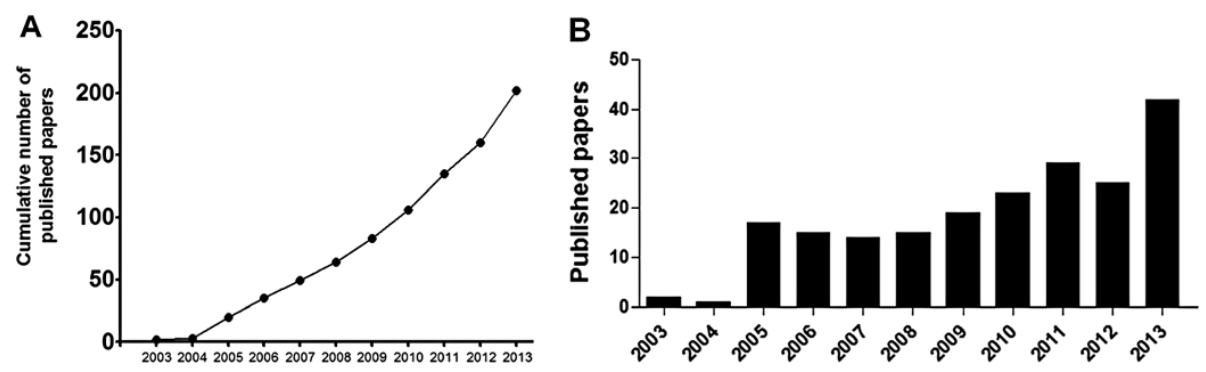

Figure 4 Cumulative number of publications relating to mimivirus and "mimivirus"/"giant viruses" over time since its discovery in 2003 (http://www.ncbi.nlm.nih.gov/pubmed)". (A) Cumulative number of publications relating to mimivirus over time. The subject was researched on Pubmed page (http://www.ncbi.nlm.nih.gov/pubmed), demonstrating the growing number of papers related to the virus since its discovery in 2003. (B) Published "mimivirus"/"giant viruses" papers per year since 2003, also according to the Pubmed website. 
increased following infection, and APMV was seem as cytopathogenic for these cells [39]. Recently, a study investigated whether human peripheral blood mononuclear cells (PBMC) can recognize APMV presence by measuring IFN induction; whether APMV can replicate in these cells; and whether replication of the virus is affected by treatment of cells with IFN type I [49]. The results showed that APMV is able to replicate in human PBMC and induce type I IFN in these cells and that it inhibits some IFN-stimulated genes (ISG) by a mechanism that is independent of viroceptors and STAT dephosphorylation [49]. It was also seen that APMV is resistant to the antiviral action of IFN alpha2 (IFNA2), but is sensitive to the antiviral action of IFN beta (IFNB1). These results not only confirm that APMV can indeed replicate in vertebrate phagocytes but also show that it is recognized by the innate immune system and that it is likely able to at least partially evade that system [49]. This interaction is most likely the result of co-evolution between APMV and vertebrate hosts, and it is strong evidence of an ancestral relationship between these organisms [49]. Recently, mouse exposure to mimivirus collagens was shown to induce anti-collagen antibodies that also targeted mouse collagen type II, and the exposure was associated with T-cell reactivity to collagen and joint inflammation [99]. Furthermore, a serologic study found reactivities to the mimivirus collagen protein L71 in 22\% of rheumatoid arthritis patients, compared to $6 \%$ of healthy-subjects. Thus, while clinical studies involving mimivirus are still a growing field, research over the past few years is strengthening the idea that mimiviruses, which are broadly distribution in our biosphere, not only have an environmental impact but are also involved in human health.

\section{Viral resistance to chemical and physical biocides}

The probable importance of APMV as a human pathogen in hospital environments has led to the need for investigating the virucidal activity of chemical biocides used for disinfection in hospitals. In a study performed in 2012, it was shown that APMV is especially resistant to alcohols but is sensitive to the action of active chlorine and glutaraldehyde, and it is able to remain stable on inanimate surfaces for 30 days, even in the absence of organic matter; this highlights the need for best strategies to control this putative pneumonia agent in hospital environments [69]. Amoebae, the hosts of several giant viruses, may act as biological platforms in the spread of pathogens such as Legionella, Parachlamydia, Mycobacterium and also APMV, representing a public health concern. In 2013 we investigated the APMV survival in certain adverse conditions when present in the intracellular environment of $A$. castellanii [100]. It was found that when APMV is inside an amoebal cell subjected to UV irradiation, heat or exposure to different chemical biocides, it remains more stable, showing that these hosts can act like natural bunkers for APMV, increasing its resistance to the viral agents used to disinfect hospital environments [100]. In addition, Acanthamoeba spp. may represent a training field for human pathogens, as several micro-organisms resisting these amoebae were concurrently found to resist human macrophages [40].

\section{Giant viruses publication indicators}

An indicator of the growth of related research fields concerning giant viruses is the recent increase in the number of publications about APMV and other giant viruses. In 2013, the number of papers related to these fields was 21fold greater than to the number of papers published in 2003, the year of APMV discovery (Figures 3 and 4). Interest in APMV also increased in internet search tools such as Google Search (Google Trends) over the years, with peaks in 2004, 2006 and 2009 (Figure 3) that most likely are related to mimivirus research hallmarks, such as its discovery, its association to virophages and studies describing APMV as a putative pneumonia agent $[5,11,57,73]$ (Figure 3 ). Currently, mimiviruses are the second group amongst NCLDVs most searched in the Google platform, and, on some occasions, even overcomes the well-known poxviruses (Figure 3).

\section{Conclusions}

As described, APMV and other giant viruses have emerged as a fascinating line of research. Each discovery regarding mimiviruses has overwhelmed scientists from different areas of expertise, which may explain why so many outstanding publications are multidisciplinary. The future of mimivirus studies might go beyond the description of bigger and more complex viruses but also may contemplate deep structural, genetic and evolutionary studies. With all this knowledge, we expect it will be possible to understand the exact role of mimiviruses in environmental dynamics and their importance as etiological agents of pneumonia in humans and other animals.

\section{Competing interests}

The authors declare that they have no competing interests.

\section{Authors' contribution}

JSA, FPD, LCS, GMA, PVB, PC, BS and EGK wrote the manuscript. PVB performed analysis in Google Trends and Pubmed. FPD performed electron microscopy analysis. JSA designed the figures. All authors read and approved the final manuscript.

\section{Acknowledgments}

We thank colleagues from Laboratório de Vírus and Aix-Marseille Université for their excellent support.

This study was supported by the Conselho Nacional de Desenvolvimento Científico e Tecnológico, Coordenação de Aperfeiçoamento de Pessoal de Nível Superior, the Fundação de Amparo à Pesquisa do Estado de Minas Gerais, Pro-Reitoria de Pesquisa da UFMG, and Centro de Microscopia da UFMG. E.G.K. is researcher of the Conselho Nacional de Desenvolvimento Científico e Tecnológico. 


\section{Author details}

${ }^{1}$ Universidade Federal de Minas Gerais, Instituto de Ciências Biológicas, Laboratório de Vírus, Avenida Antônio Carlos, 6627, Caixa Postal 486, Bloco F4, Sala 258, 31270-901 Belo Horizonte, Minas Gerais, Brazil. '2URMITE, UM63, CNRS 7278, IRD 198, Inserm 1095, Aix Marseille Universite, Marseille, France.

Received: 17 March 2014 Accepted: 16 June 2014

Published: 30 June 2014

\section{References}

1. Rohwer F, Prangishvili $D$, Lindell $D$ : Roles of viruses in the environment. Environ Microbiol 2009, 11:2771-2774.

2. Breitbart M, Miyake JH, Rohwer F: Global distribution of nearly identical phage-encoded DNA sequences. FEMS Microbiol Lett 2004, 236:249-256.

3. Short CM, Suttle CA: Nearly identical bacteriophage structural gene sequences are widely distributed in both marine and freshwater environments. Appl Environ Microbiol 2005, 71:480-486.

4. Van Etten JL, Lane LC, Dunigan DD: DNA viruses: the really big ones (giruses). Annu Rev Microbiol 2010, 64:83-99.

5. La Scola B, Audic S, Robert C, Jungang L, de Lamballerie X, Drancourt M, Birtles R, Claverie JM, Raoult D: A giant virus in amoebae. Science 2003, 299:2033.

6. Moreira D, Brochier-Armanet C: Giant viruses, giant chimeras: the multiple evolutionary histories of Mimivirus genes. BMC Evol Biol 2008, 8:12

7. Hingamp P, Grimsley N, Acinas SG, Clerissi C, Subirana L, Poulain J, Ferrera I, Sarmento H, Villar E, Lima-Mendez G, Faust K, Sunagawa S, Claverie JM, Moreau H, Desdevises Y, Bork P, Raes J, de Vargas C, Karsenti E, KandelsLewis $\mathrm{S}$, Jaillon O, Not F, Pesant $\mathrm{S}$, Wincker $\mathrm{P}$, Ogata $\mathrm{H}$ : Exploring nucleocytoplasmic large DNA viruses in Tara Oceans microbial metagenomes. ISME J 2013, 7:1678-1695.

8. Kroon EG, Mota BE, Abrahao JS, da Fonseca FG, de Souza Trindade G: Zoonotic Brazilian Vaccinia virus: from field to therapy. Antiviral Res 2011, 92:150-163.

9. Claverie JM, Abergel C: Mimivirus: the emerging paradox of quasiautonomous viruses. Trends Genet 2010, 26:431-437.

10. Claverie JM, Abergel C, Ogata H: Mimivirus. Curr Top Microbiol Immunol 2009, 328:89-121.

11. La Scola B, Desnues C, Pagnier I, Robert C, Barrassi L, Fournous G, Merchat M, Suzan-Monti M, Forterre P, Koonin E, Raoult D: The virophage as a unique parasite of the giant mimivirus. Nature 2008, 455:100-104.

12. Desnues C, Raoult D: Inside the lifestyle of the virophage. Intervirology 2010, 53:293-303.

13. Arslan D, Legendre M, Seltzer $V$, Abergel C, Claverie JM: Distant Mimivirus relative with a larger genome highlights the fundamental features of Megaviridae. Proc Natl Acad Sci U S A 2011, 108:17486-17491.

14. Desnues C, La Scola B, Yutin N, Fournous G, Robert C, Azza S, Jardot P, Monteil S, Campocasso A, Koonin EV, Raoult D: Provirophages and transpovirons as the diverse mobilome of giant viruses. Proc Natl Acad Sci U S A 2012, 109:18078-18083.

15. Yoosuf N, Yutin N, Colson P, Shabalina SA, Pagnier I, Robert C, Azza S, Klose T, Wong J, Rossmann MG, La Scola B, Raoult D, Koonin E: Related giant viruses in distant locations and different habitats: Acanthamoeba polyphaga moumouvirus represents a third lineage of the Mimiviridae that is close to the megavirus lineage. Genome Biol Evol 2012 4:1324-1330.

16. Boughalmi M, Pagnier I, Aherfi S, Colson P, Raoult D, La Scola B: First isolation of a giant virus from wild Hirudo medicinalis leech: Mimiviridae isolation in Hirudo medicinalis. Viruses 2013, 5:2920-2930.

17. Yoosuf N, Pagnier I, Fournous G, Robert C, La Scola B, Raoult D, Colson P. Complete genome sequence of Courdo11 virus, a member of the family Mimiviridae. Virus Genes 2014, 48:218-223.

18. Boyer M, Yutin N, Pagnier I, Barrassi L, Fournous G, Espinosa L, Robert C, Azza S, Sun S, Rossmann MG, Suzan-Monti M, La Scola B, Koonin EV, Raoult $D$ : Giant Marseillevirus highlights the role of amoebae as a melting pot in emergence of chimeric microorganisms. Proc Natl Acad Sci U S A 2009, 106:21848-21853.

19. Philippe $N$, Legendre M, Doutre G, Coute Y, Poirot O, Lescot M, Arslan D, Seltzer V, Bertaux L, Bruley C, Garin J, Claverie JM, Abergel C: Pandoraviruses: amoeba viruses with genomes up to $2.5 \mathrm{Mb}$ reaching that of parasitic eukaryotes. Science 2013, 341:281-286.
20. Legendre M, Bartoli J, Shmakova L, Jeudy S, Labadie K, Adrait A, Lescot M, Poirot O, Bertaux L, Bruley C, Couté Y, Rivkina E, Abergel C, Claverie J: Thirty-thousand-year-old distant relative of giant icosahedral DNA viruses with a pandoravirus morphology. Proc Natl Acad Sci U S A 2014, 111:4274-4279.

21. Iyer $L M$, Aravind $L$, Koonin EV: Common origin of four diverse families of large eukaryotic DNA viruses. J Virol 2001, 75:11720-11734.

22. Colson P, Gimenez G, Boyer M, Fournous G, Raoult D: The giant Cafeteria roenbergensis virus that infects a widespread marine phagocytic protist is a new member of the fourth domain of Life. PLoS One 2011, 6:e18935.

23. Desnues $C$, Boyer M, Raoult D: Sputnik, a virophage infecting the viral domain of life. Adv Virus Res 2012, 82:63-89.

24. Colson P, de Lamballerie X, Fournous G, Raoult D: Reclassification of giant viruses composing a fourth domain of life in the new order Megavirales. Intervirology 2012, 55:321-332.

25. Nasir A, Kim KM, Caetano-Anolles G: Giant viruses coexisted with the cellular ancestors and represent a distinct supergroup along with superkingdoms Archaea, Bacteria and Eukarya. BMC Evol Biol 2012, 12:156.

26. Boyer M, Madoui MA, Gimenez G, La Scola B, Raoult D: Phylogenetic and phyletic studies of informational genes in genomes highlight existence of a 4 domain of life including giant viruses. PLoS One 2010, 5:e15530.

27. Colson P, De Lamballerie X, Yutin N, Asgari S, Bigot Y, Bideshi DK, Cheng XW, Federici BA, Van Etten JL, Koonin EV, La Scola B, Raoult D: "Megavirales", a proposed new order for eukaryotic nucleocytoplasmic large DNA viruses. Arch Virol 2013, 158:2517-2521.

28. Colson P, Pagnier I, Yoosuf N, Fournous G, La Scola B, Raoult D: "Marseilleviridae", a new family of giant viruses infecting amoebae. Arch Virol 2013, 158:915-920.

29. Yutin N, Koonin EV: Hidden evolutionary complexity of NucleoCytoplasmic Large DNA viruses of eukaryotes. Virol J 2012, 9:161.

30. Yutin N, Koonin EV: Evolution of DNA ligases of nucleo-cytoplasmic large DNA viruses of eukaryotes: a case of hidden complexity. Biol Direct 2009, 4:51.

31. La Scola B, Campocasso A, N'Dong R, Fournous G, Barrassi L, Flaudrops C, Raoult D: Tentative characterization of new environmental giant viruses by MALDI-TOF mass spectrometry. Intervirology 2010, 53:344-353.

32. Yutin N, Colson P, Raoult D, Koonin EV: Mimiviridae: clusters of orthologous genes, reconstruction of gene repertoire evolution and proposed expansion of the giant virus family. Virol J 2013, 10:106.

33. Pagnier I, Reteno DG, Saadi H, Boughalmi M, Gaia M, Slimani M, Ngounga T, Bekliz M, Colson P, Raoult D, La Scola B: A decade of improvements in Mimiviridae and Marseilleviridae isolation from amoeba. Intervirology 2013, 56:354-363.

34. Marciano-Cabral F, Cabral G: Acanthamoeba spp. as agents of disease in humans. Clin Microbiol Rev 2003, 16:273-307.

35. Costa AO, Castro EA, Ferreira GA, Furst C, Crozeta MA, Thomaz-Soccol V: Characterization of acanthamoeba isolates from dust of a public hospital in Curitiba, Parana, Brazil. J Eukaryot Microbiol 2010, 57:70-75.

36. Rohr U, Weber S, Michel R, Selenka F, Wilhelm M: Comparison of free-living amoebae in hot water systems of hospitals with isolates from moist sanitary areas by identifying genera and determining temperature tolerance. Appl Environ Microbiol 1998, 64:1822-1824.

37. Coulon C, Collignon A, McDonnell G, Thomas V: Resistance of Acanthamoeba cysts to disinfection treatments used in health care settings. J Clin Microbiol 2010, 48:2689-2697.

38. Visvesvara GS: Infections with free-living amebae. Handb Clin Neurol 2013 114:153-168.

39. Ghigo E, Kartenbeck J, Lien P, Pelkmans L, Capo C, Mege JL, Raoult D: Ameobal pathogen mimivirus infects macrophages through phagocytosis. PLoS Pathog 2008, 4:e1000087.

40. Greub G, Raoult D: Microorganisms resistant to free-living amoebae. Clin Microbiol Rev 2004, 17:413-433.

41. Kilvington S, Price J: Survival of Legionella pneumophila within cysts of Acanthamoeba polyphaga following chlorine exposure. J Appl Bacteriol 1990, 68:519-525.

42. Matsuo J, Hayashi Y, Nakamura S, Sato M, Mizutani Y, Asaka M, Yamaguchi $\mathrm{H}$ : Novel Parachlamydia acanthamoebae quantification method based on coculture with amoebae. Appl Environ Microbiol 2008, 74:6397-6404.

43. Harriff M, Bermudez LE: Environmental amoebae and mycobacterial pathogenesis. Methods Mol Biol 2009, 465:433-442.

44. Claverie JM, Grzela R, Lartigue A, Bernadac A, Nitsche S, Vacelet J, Ogata H, Abergel C: Mimivirus and Mimiviridae: giant viruses with an increasing 
number of potential hosts, including corals and sponges. J Invertebr Pathol 2009, 101:172-180.

45. Khan M, La Scola B, Lepidi H, Raoult D: Pneumonia in mice inoculated experimentally with Acanthamoeba polyphaga mimivirus. Microb Pathog 2007, 42:56-61.

46. Popgeorgiev N, Boyer M, Fancello L, Monteil S, Robert C, Rivet R, Nappez C, Azza S, Chiaroni J, Raoult D, Desnues C: Marseillevirus-like virus recovered from blood donated by asymptomatic humans. J Infect Dis 2013, 208:1042-1050.

47. Hoffmann B, Scheuch M, Hoper D, Jungblut R, Holsteg M, Schirrmeier H, Eschbaumer M, Goller KV, Wernike K, Fischer M, Breithaupt A, Mettenleiter TC, Beer M: Novel orthobunyavirus in Cattle, Europe, 2011. Emerg Infect Dis 2012, 18:469-472.

48. Dornas FP, Rodrigues FP, Boratto PV, Silva LC, Ferreira PC, Bonjardim CA, Trindade GS, Kroon EG, La Scola B, Abrahao JS: Mimivirus Circulation among Wild and Domestic Mammals, Amazon Region, Brazil. Emerg Infect Dis 2014, 20:469-472.

49. Silva LC, Almeida GM, Oliveira DB, Dornas FP, Campos RK, La Scola B, Ferreira PC, Kroon EG, Abrahao JS: A resourceful giant: APMV is able to interfere with the human type I interferon system. Microbes Infect 2013, 16:187-195.

50. Saadi H, Reteno DG, Colson P, Aherfi S, Minodier P, Pagnier I, Raoult D, La Scola B: Shan virus: a new mimivirus isolated from the stool of a Tunisian patient with pneumonia. Intervirology 2013, 56:424-429.

51. Colson P, La Scola B, Raoult D: Giant viruses of amoebae as potential human pathogens. Intervirology 2013, 56:376-385.

52. Saadi H, Pagnier I, Colson P, Cherif JK, Beji M, Boughalmi M, Azza S, Armstrong N, Robert C, Fournous G, La Scola B, Raoult D: First isolation of Mimivirus in a patient with pneumonia. Clin Infect Dis 2013, 57:e127-e134.

53. Colson P, Fancello L, Gimenez G, Armougom F, Desnues C, Fournous G, Yoosuf N, Million M, La Scola B, Raoult D: Evidence of the megavirome in humans. J Clin Virol 2013, 57:191-200

54. Bousbia S, Papazian L, Saux P, Forel JM, Auffray JP, Martin C, Raoult D, La Scola B: Serologic prevalence of amoeba-associated microorganisms in intensive care unit pneumonia patients. PLoS One 2013, 8:e58111.

55. Vincent A, La Scola B, Forel JM, Pauly V, Raoult D, Papazian L: Clinical significance of a positive serology for mimivirus in patients presenting a suspicion of ventilator-associated pneumonia. Crit Care Med 2009, 37:111-118.

56. Raoult $D$, Renesto $P$, Brouqui $P$ : Laboratory infection of a technician by mimivirus. Ann Intern Med 2006, 144:702-703.

57. La Scola B, Marrie TJ, Auffray JP, Raoult D: Mimivirus in pneumonia patients. Emerg Infect Dis 2005, 11:449-452.

58. Azza S, Cambillau C, Raoult D, Suzan-Monti M: Revised Mimivirus major capsid protein sequence reveals intron-containing gene structure and extra domain. BMC Mol Biol 2009, 10:39.

59. McPherson A, Kuznetsov YG: Atomic force microscopy investigation of viruses. Methods Mol Biol 2011, 736:171-195

60. Klose T, Kuznetsov YG, Xiao C, Sun S, McPherson A, Rossmann MG: The three-dimensional structure of Mimivirus. Intervirology 2010, $53: 268-273$

61. Claverie JM, Abergel C: Mimivirus and its virophage. Annu Rev Genet 2009, 43:49-66.

62. Mutsafi Y, Shimoni E, Shimon A, Minsky A: Membrane assembly during the infection cycle of the giant Mimivirus. PLoS Pathog 2013, 9:e1003367.

63. Xiao C, Kuznetsov YG, Sun S, Hafenstein SL, Kostyuchenko VA, Chipman PR, Suzan-Monti M, Raoult D, McPherson A, Rossmann MG: Structural studies of the giant mimivirus. PLOS Biol 2009, 7:e92.

64. Zauberman N, Mutsafi Y, Halevy DB, Shimoni E, Klein E, Xiao C, Sun S, Minsky A: Distinct DNA exit and packaging portals in the virus Acanthamoeba polyphaga mimivirus. PLOS Biol 2008, 6:e114

65. Dornas FP, Silva LC, de Almeida GM, Campos RK, Boratto PV, Franco-Luiz AP, La Scola B, Ferreira PC, Kroon EG, Abrahao JS: Acanthamoeba polyphaga mimivirus stability in environmental and clinical substrates: implications for virus detection and isolation. PLoS One 2014, 9:e87811.

66. Campos RK, Andrade KR, Ferreira PC, Bonjardim CA, La Scola B, Kroon EG, Abrahao JS: Virucidal activity of chemical biocides against mimivirus, a putative pneumonia agent. J Clin Virol 2012, 55:323-328.

67. Slimani M, Pagnier I, Boughalmi M, Raoult D, La Scola B: Alcohol disinfection procedure for isolating giant viruses from contaminated samples. Intervirology 2013, 56:434-440.
68. Legendre M, Santini S, Rico A, Abergel C, Claverie JM: Breaking the 1000gene barrier for Mimivirus using ultra-deep genome and transcriptome sequencing. Virol J 2011, 8:99.

69. Colson P, Raoult D: Gene repertoire of amoeba-associated giant viruses. Intervirology 2010, 53:330-343.

70. Renesto P, Abergel C, Decloquement P, Moinier D, Azza S, Ogata H, Fourquet $P$, Gorvel JP, Claverie JM: Mimivirus giant particles incorporate a large fraction of anonymous and unique gene products. J Virol 2006, 80:11678-11685.

71. Saini HK, Fischer D: Structural and functional insights into Mimivirus ORFans. BMC Genomics 2007, 8:115.

72. Hakim M, Ezerina D, Alon A, Vonshak O, Fass D: Exploring ORFan domains in giant viruses: structure of mimivirus sulfhydryl oxidase R596. PLoS One 2012, 7:e50649.

73. Raoult D, Audic S, Robert C, Abergel C, Renesto P, Ogata H, La Scola B, Suzan M, Claverie JM: The 1.2-megabase genome sequence of Mimivirus. Science 2004, 306:1344-1350.

74. Abergel C, Rudinger-Thirion J, Giege R, Claverie JM: Virus-encoded aminoacyl-tRNA synthetases: structural and functional characterization of mimivirus TyrRS and MetRS. J Virol 2007, 81:12406-12417.

75. Colson P, Fournous G, Diene SM, Raoult D: Codon usage, amino acid usage, transfer RNA and amino-acyl-tRNA synthetases in Mimiviruses. Intervirology 2013, 56:364-375.

76. Boyer M, Azza S, Barrassi L, Klose T, Campocasso A, Pagnier I, Fournous G, Borg A, Robert C, Zhang X, Desnues C, Henrissat B, Rossmann MG, La Scola $B$, Raoult D: Mimivirus shows dramatic genome reduction after intraamoebal culture. Proc Natl Acad Sci U S A 2011, 108:10296-10301.

77. Colson P, Raoult D: Lamarckian evolution of the giant Mimivirus in allopatric laboratory culture on amoebae. Front Cell Infect Microbiol 2012, 2:91.

78. Mutsafi Y, Zauberman N, Sabanay I, Minsky A: Vaccinia-like cytoplasmic replication of the giant Mimivirus. Proc Natl Acad Sci U S A 2010, 107:5978-5982.

79. Kuznetsov YG, Klose T, Rossmann M, McPherson A: Morphogenesis of mimivirus and its viral factories: an atomic force microscopy study of infected cells. J Virol 2013, 87:11200-11213.

80. Suhre K, Audic S, Claverie JM: Mimivirus gene promoters exhibit an unprecedented conservation among all eukaryotes. Proc Natl Acad Sci U S A 2005, 102:14689-14693.

81. Campos RK, Boratto PV, Assis FL, Aguiar ERGR, Silva LCF, Albarnaz JD, Dornas FP, Trindade GS, Ferreira PCP, Marques JT, Roberts C, Raoult D, Kroon EG, La Scola B, Abrahao JS: Samba virus: a novel mimivirus from a giant rain forest, the Brazilian Amazon. Virol J 2014, 11:95.

82. Dai W, Fu C, Raytcheva D, Flanagan J, Khant HA, Liu X, Rochat RH, HaasePettingell C, Piret J, Ludtke SJ, Nagayama K, Schmid MF, King JA, Chiu W Visualizing virus assembly intermediates inside marine cyanobacteria. Nature 2013, 502:707-710.

83. Sheik AR, Brussaard CP, Lavik G, Lam P, Musat N, Krupke A, Littmann S, Strous M, Kuypers MM: Responses of the coastal bacterial community to viral infection of the algae Phaeocystis globosa. ISME J 2014, 8:212-225.

84. Fischer MG, Allen MJ, Wilson WH, Suttle CA: Giant virus with a remarkable complement of genes infects marine zooplankton.

Proc Natl Acad Sci U S A 2010, 107:19508-19513.

85. Monier A, Larsen JB, Sandaa RA, Bratbak G, Claverie JM, Ogata H: Marine mimivirus relatives are probably large algal viruses. Virol $J$ 2008, 5:12.

86. Ghedin E, Claverie JM: Mimivirus relatives in the Sargasso sea. Virol J 2005, 2:62.

87. Claverie JM: Giant virus in the sea: Extending the realm of Megaviridae to Viridiplantae. Commun Integr Biol 2013, 6:e25685.

88. Williams TA, Embley TM, Heinz E: Informational gene phylogenies do not support a fourth domain of life for nucleocytoplasmic large DNA viruses. PLoS One 2011, 6:e21080

89. Piacente F, Marin M, Molinaro A, De Castro C, Seltzer V, Salis A, Damonte G, Bernardi C, Claverie JM, Abergel C, Tonetti M: Giant DNA virus mimivirus encodes pathway for biosynthesis of unusual sugar 4-amino-4,6dideoxy-D-glucose (Viosamine). J Biol Chem 2012, 287:3009-3018.

90. Luther KB, Hulsmeier AJ, Schegg B, Deuber SA, Raoult D, Hennet T: Mimivirus collagen is modified by bifunctional lysyl hydroxylase and glycosyltransferase enzyme. J Biol Chem 2011, 286:43701-43709.

91. Fischer MG, Suttle CA: A virophage at the origin of large DNA transposons. Science 2011, 332:231-234 
92. Yutin N, Raoult D, Koonin EV: Virophages, polintons, and transpovirons: a complex evolutionary network of diverse selfish genetic elements with different reproduction strategies. Virol J 2013, 10:158.

93. Turner P, Turner C, Watthanaworawit W, Carrara V, Cicelia N, Deglise C, Phares C, Ortega L, Nosten F: Respiratory virus surveillance in hospitalised pneumonia patients on the Thailand-Myanmar border. BMC Infect Dis 2013, 13:434.

94. Marrie TJ, Costain N, La Scola B, Patrick W, Forgie S, Xu Z, McNeil SA: The role of atypical pathogens in community-acquired pneumonia. Semin Respir Crit Care Med 2012, 33:244-256.

95. Vanspauwen MJ, Schnabel RM, Bruggeman CA, Drent M, van Mook WN, Bergmans DC, Linssen CF: Mimivirus is not a frequent cause of ventilatorassociated pneumonia in critically ill patients. J Med Virol 2013, 85:1836-1841.

96. Dare RK, Chittaganpitch M, Erdman DD: Screening pneumonia patients for mimivirus. Emerg Infect Dis 2008, 14:465-467.

97. Costa C, Bergallo M, Astegiano S, Terlizzi ME, Sidoti F, Solidoro P, Cavallo R: Detection of Mimivirus in bronchoalveolar lavage of ventilated and nonventilated patients. Intervirology 2012, 55:303-305.

98. Vanspauwen MJ, Franssen FM, Raoult D, Wouters EF, Bruggeman CA, Linssen CF: Infections with mimivirus in patients with chronic obstructive pulmonary disease. Respir Med 2012, 106:1690-1694

99. Shah N, Hulsmeier AJ, Hochhold N, Neidhart M, Gay S, Hennet T: Exposure to mimivirus collagen promotes arthritis. J Virol 2014, 88:838-845.

100. Boratto PV, Dornas FP, Andrade KR, Rodrigues R, Peixoto F, Silva LC, La Scola B, Costa AO, de Almeida GM, Kroon EG, Abrahao JS: Amoebas as mimivirus bunkers: increased resistance to UV light, heat and chemical biocides when viruses are carried by amoeba hosts. Arch Virol 2013, 159:1039-1043.

doi:10.1186/1743-422X-11-120

Cite this article as: Abrahão et al:: Acanthamoeba polyphaga mimivirus and other giant viruses: an open field to outstanding discoveries. Virology Journal 2014 11:120.

\section{Submit your next manuscript to BioMed Central and take full advantage of:}

- Convenient online submission

- Thorough peer review

- No space constraints or color figure charges

- Immediate publication on acceptance

- Inclusion in PubMed, CAS, Scopus and Google Scholar

- Research which is freely available for redistribution 